\title{
Modeling and Simulation of a Wind-diesel Hybrid Power System for Isolated Areas
}

\author{
Khaireddine Allali \\ Laboratoire d'Electrotechnique \\ d'Annaba \\ Badji Mokhtar University- \\ Annaba,P.O.Box 12, \\ Annaba 23000, Algeria
}

\author{
El-Bahi Azzag \\ Laboratoire d'Electrotechnique \\ d'Annaba \\ Badji Mokhtar University- \\ Annaba,P.O.Box 12, \\ Annaba 23000, Algeria
}

\author{
Nabil Kahoul \\ Laboratoire d'Electrotechnique \\ d'Annaba \\ Badji Mokhtar University- \\ Annaba,P.O.Box 12, \\ Annaba 23000, Algeria
}

\begin{abstract}
In many isolated areas situated in south Algerian, the diesel generators are the major source of electric energy. Indeed, the alimentation power of these remote areas still poses order problems (technical, economical and ecological). The electricity produced with the help of diesel generators is relatively inefficient, very expensive and responsible for the emission of greenhouse gas. These isolated areas have significant wind energy potential; which puts him in good position for the exploitation of clean and sustainable wind energy. The use of Twinning Wind-Diesel (TWD) is widely recommended especially to reduce operating deficits. However, the profitability of TWD is attained the condition to obtain a high penetration ratio of wind energy: which is possible only when using energy system storage. For hybrid energy storage systems plays a vital role, different storage technologies, we chosen for our study the battery energy storage system (BESS) still represent the most cost-effective technology. The subject of this paper is to present the modeling of a Wind Diesel Hybrid System (WDHS) comprising a Diesel Generator (DG), a Wind Turbine Generator (WTG), the consumer load, a Ni-MH Battery and a Distributed Control System (DCS).
\end{abstract}

\section{Keywords}

Wind turbine, diesel generator, autonomous grid, storage system, management, modeling.

\section{INTRODUCTION}

Energy is one of the major inputs for the economic development of any country. In the case of the developing countries, the energy sector assumes a critical importance in view of the ever increasing energy needs requiring huge investments to meet them. The growth of the world's human population has created several problems. One of them is global warming caused by the abundance of $\mathrm{CO}_{2}$ in the atmosphere. Many of these gases are produced from electrical plants burning fossil fuel all over the world [1].

The electrical energy demand is increasing constantly and this demand has to be met by a planned electrical power generation programmer. Although electrical energy is environmentally the most benign form of energy, its production is routed through burning of conventional fossil fuel or nuclear energy or hydro resources. All of these, in addition to other disadvantages, give rise to environmental issues of varied nature. To minimize the environmental degradations, one of the solutions is to utilize wind energy in favorable remote sites, away from the centralized energy supply systems [2].

Nevertheless, in isolated areas, electrical energy is often produced with the help of diesel generators such as the Algerian Sahara (Adrar, Bechar, In Salah, Timimoun, Tindouf, Amenas, etc). But numerous isolated areas have significant wind energy potential. It is then interesting to associate with a diesel some wind generators as diesel electricity is generally more expensive than wind electricity. To reduce fuel consumption and power variations of the diesel, an energy storage system can be associated with the wind-diesel system [3]. A hybrid wind-diesel power generation systems have a great potential in the application of providing energy supply for remote communities and facilities. Compared to the traditional diesel system, hybrid power plants can offer many advantages such as additional capacity, being more environmentally friendly, potential reduction of cost, etc. [4].The subject of this paper is to present the modeling and simulation of an isolated Wind Diesel Hybrid System (WDHS) comprising a Diesel Generator (DG), a Wind Turbine Generator (WTG), the consumer load, a Ni-MH battery based Energy Storage System (BESS). The model modeling of hybrid system is based on control strategy to optimize the power output, regulate voltage and frequency transmitted to consumers.

\section{WIND ENERGY RESOURCE IN ALGERIA}

All The wind energy resource in Algeria varies greatly from one place to another. This is mainly due to a very diverse topography and climate. Algeria is a moderate wind regime ( 2 to $6.5 \mathrm{~m} / \mathrm{s}$ ). The map shown in Figure 1 shows that the South is characterized by higher speeds than the North, especially in the South-West, with greater speeds than $4 \mathrm{~m} / \mathrm{s}$, that exceed the value of $6 \mathrm{~m} / \mathrm{s}$ at Adrar region. On the North, we note that the overall average speed is low [5]. 


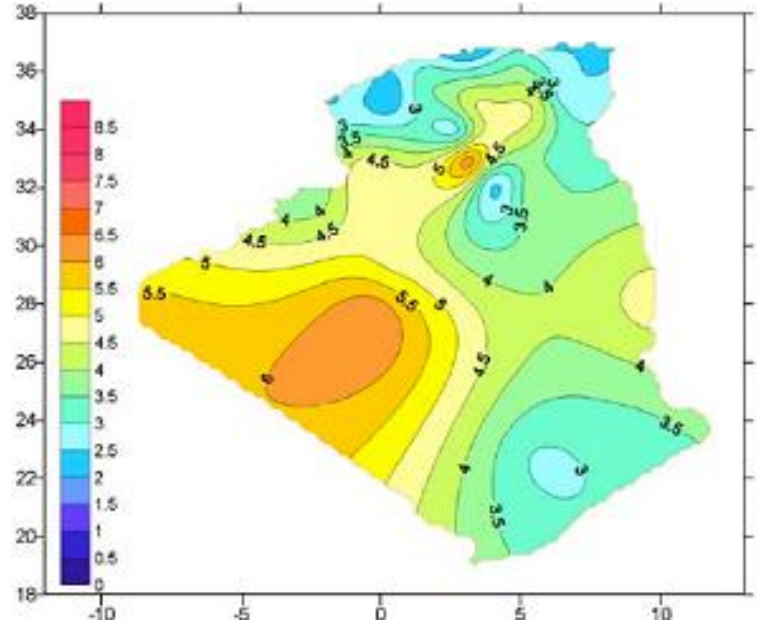

Fig 1: Annual maps of wind speed in Algeria at $10 \mathrm{~m}$ high

The climate data of wind speed recorded at Adrar region (Algeria) for the year 2012 were measured at the weather station of the Renewable Energy Research Unit in Saharian Medium (URER-MS) Adrar.(see Table 1 below), [6].

Table 1. Climate data for a studied site

\begin{tabular}{|c|c|c|c|c|c|c|c|c|c|c|c|c|}
\hline 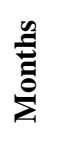 & 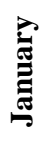 & 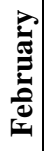 & 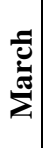 & $\frac{\vec{z}}{2}$ & $\stackrel{\overrightarrow{\mathrm{J}}}{\mathrm{\Sigma}}$ & 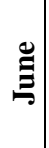 & 롤 & $\begin{array}{l}\vec{v} \\
\overline{0} \\
\vec{z} \\
\vec{z}\end{array}$ & 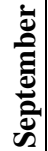 & $\begin{array}{l}\dot{\bar{d}} \\
\frac{0}{0} \\
\frac{0}{0}\end{array}$ & $\begin{array}{l}\dot{\Xi} \\
\stackrel{0}{\Xi} \\
\bar{\Xi} \\
\bar{Z} \\
\mathbf{Z}\end{array}$ & 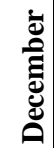 \\
\hline $\begin{array}{c}\boldsymbol{v} \\
(\mathbf{m} / \mathbf{s})\end{array}$ & $\begin{array}{l}\text { f } \\
\text { ó }\end{array}$ & $\begin{array}{l}\text { ते } \\
\text {. }\end{array}$ & $\begin{array}{l}2 \\
0 \\
0\end{array}$ & ले & $\begin{array}{l}\hat{n} \\
0\end{array}$ & $\hat{n}$ & $\begin{array}{l}\infty \\
\stackrel{2}{\sim}\end{array}$ & $\begin{array}{l}\vec{J}_{0} \\
6\end{array}$ & $\begin{array}{l}\dot{\Delta} \\
\stackrel{\nabla}{*}\end{array}$ & $\begin{array}{l}\infty \\
\stackrel{+}{+}\end{array}$ & $\begin{array}{l}0 \\
\infty \\
\forall\end{array}$ & $\begin{array}{l}\infty \\
\sim \\
n \\
n\end{array}$ \\
\hline
\end{tabular}

\section{WIND-DIESEL HYBRID SYSTEM}

\section{(WDHS)}

\subsection{Description of a WDHS}

The underlying hybrid wind-diesel system is illustrated in Figure 2. The hybrid generation system is composed of a wind turbine generator (WTG), diesel generator (DG), battery bank, consumer load, power electronic converters (AC/DC rectifier, DC/AC inverter), monitoring system, distributed control system, switches and relays, controller and other accessory devices and cables [7-8].

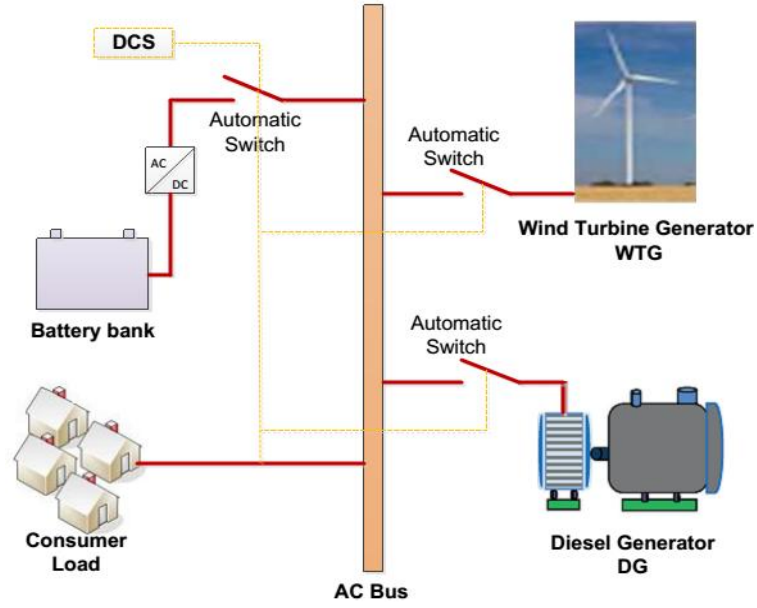

Fig 2: Schematic diagram of the hybrid wind-diesel

\section{generation power system}

\subsection{Operating regimes of a WDHS}

Depending on the strength of the wind, there are three modes for systems with high penetration, (see Figure 3) [8]:

1. Weak winds $\left(v_{w} \leq 3 \mathrm{~m} / \mathrm{s}\right)$ : diesel only.

2. Moderate winds $\left(3 \mathrm{~m} / \mathrm{s}<v_{w} \leq 10 \mathrm{~m} / \mathrm{s}\right)$ wind turbines and diesels in service.

3. Strong winds $\left(v_{w}>10 \mathrm{~m} / \mathrm{s}\right)$ wind only.

Where: $v_{w}$ is the wind speed upstream of the turbine.

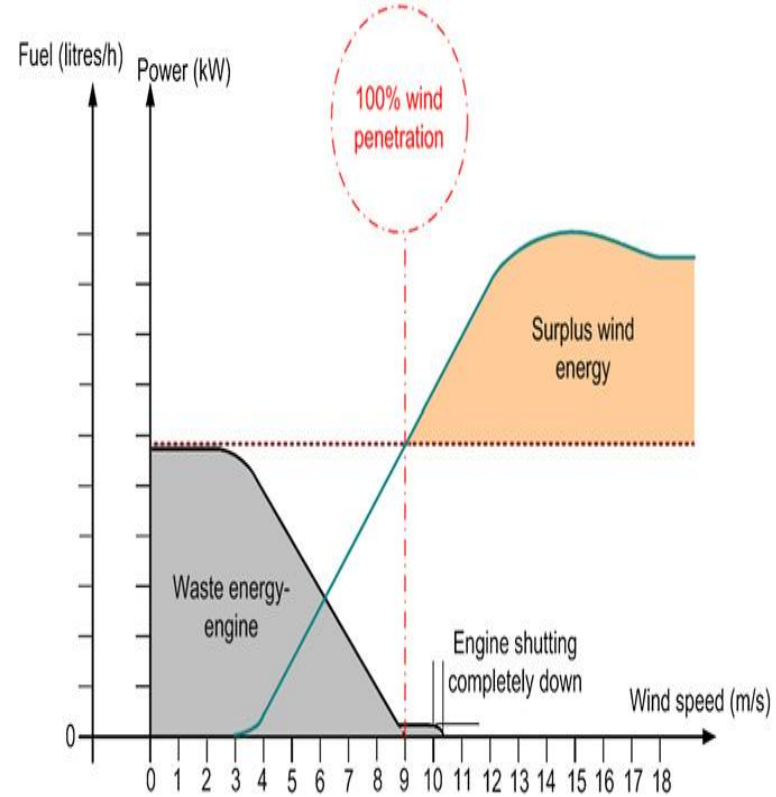

Fig 3: Variation of energy covered by a WDHS and diese consumption as a function of wind speed

\section{SIMULATION MODELING OF HYBRID SYSTEM COMPONENTS}

\subsection{Modeling of wind turbine system}

\subsubsection{Wind model}

The wind speed can be modeled by a sum of some harmonious [9]:

$$
V_{v}(t)=B+\frac{2}{\pi} \sum A_{i} \cdot \cos \left(\omega_{i} \cdot t+\varphi_{i}\right)
$$

Where: $\boldsymbol{B}$ is the constant and $\boldsymbol{A}_{\boldsymbol{i}}$ is the amplitudes of harmonious, $\omega_{\mathrm{i}}, \boldsymbol{\varphi}_{i}$ represent respectively, the pulsations and phases.

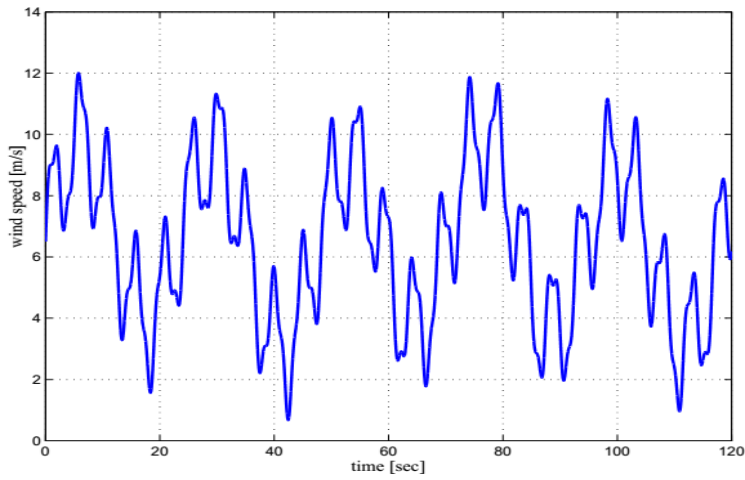




\section{Fig 4: The wind speed profile}

\subsubsection{Wind turbine model}

A wind turbine can only convert a certain percentage of the captured wind power. This percentage is represented by $\boldsymbol{C}_{\boldsymbol{P}}$ which is a function of the wind speed, the turbine speed and the pitch angle of any specific wind turbine blades [10-11].

The mechanical power $\mathbf{P}_{\text {mec }}$ extracted from the wind is mainly governed by three quantities namely: the area swept by turbine blades $\mathbf{S}$, the wind speed $\boldsymbol{v}_{\boldsymbol{w}}$ and the rotor power coefficient $\boldsymbol{C}_{\boldsymbol{p}}$ by following equation [12]

$$
P_{\text {mec }}=\frac{1}{2} \rho \cdot S \cdot v_{\omega}^{3} \cdot C_{p}(\lambda, \beta)
$$

Where $\rho$ is the air density $\left[\mathrm{kg} / \mathrm{m}^{3}\right]$

In this paper, $\mathbf{C}_{\mathbf{P}}$ is the power coefficient of rotor has been defined by Eq. (3), [12]. Power coefficient is a function of tip speed ratio (TSR) $\lambda$ defined by Eq. (4) and pitch angel $\boldsymbol{\beta}$. The wind turbine considered in this work is stall controlled, so pitch angel is kept constant, is considered zero where the $\boldsymbol{C}_{\boldsymbol{P}}$ value would be 0.48 and $\boldsymbol{C}_{\boldsymbol{P}}$ is a function of $\lambda(\lambda=8.1)$, [10-11].

$$
\begin{gathered}
C_{p}=0.22\left(116 . \lambda_{i}-0.4 \beta-5\right) e^{-12.5 \lambda_{i}} \\
\lambda=\frac{\omega_{r} \cdot R}{v_{\omega}}
\end{gathered}
$$

Where $\boldsymbol{\Omega}_{\mathbf{r}}$ is the rotor rotational speed and $\mathbf{R}$ is the wind turbine rotor radius.

Thus the maximum power captured from the wind is given by [13]:

$$
P_{m e c}^{\max }=\frac{1}{2} \rho \cdot S \cdot v_{\omega}^{3} \cdot C_{p}^{\max }\left(\lambda_{o p t}, \beta\right)
$$

\subsubsection{PMSG model}

The model of permanent magnet synchronous generators (PMSG) is composed of two electrical differential equations and one mechanical differential equation. The electrical equations, expressed in direct (d) quadrature (q) coordinate are given by [14]:

$$
\left\{\begin{array}{l}
U_{d}=-R_{s} \cdot i_{d}-L_{d} \frac{d_{i d}}{d t}-\omega_{r} \cdot L_{q} \cdot i_{q} \\
U_{q}=-R_{s} \cdot i_{q}-L_{q} \frac{d_{i q}}{d t}+\omega_{r} \cdot L_{d} \cdot i_{d}+\omega_{r} \cdot \varphi_{f} \\
T_{e}-T_{\text {mес }}-\Omega_{r} \cdot F=J_{r} \cdot \frac{d \Omega_{r}}{d t}
\end{array}\right.
$$

Where $\boldsymbol{U}$ denotes voltage, $\boldsymbol{i}$ denotes current, $\boldsymbol{\varphi}$ represents magnetic flux, $\boldsymbol{R}_{s}$ denotes resistance and $\boldsymbol{L}$ inductance, indexes $\boldsymbol{d}$ and $\boldsymbol{q}$ stand for the direct and quadrature components, $\omega_{\mathbf{r}}$ is the generator electrical speed $\left(\omega_{\mathrm{r}}=\right.$ p. $\left.\Omega_{\mathrm{r}}\right)$ and $\varphi_{\mathrm{f}}$ is the magnetic flux of the permanent magnets.

$\mathbf{T}_{\text {mec }}$ is the mechanical torque from the generator shaft, $\mathbf{T}_{\mathbf{e}}$ is the generator electromechanical torque, $\mathbf{J}_{\mathbf{r}}$ is the aerodynamic rotor inertia, $\boldsymbol{\Omega}_{\mathrm{r}}$ is the generator angular velocity, $\mathbf{F}$ is the viscous friction coefficient from the generator shaft and $\mathbf{p}$ is the number of pair poles.

\subsection{Modeling of diesel generator}

The DG is generally constituted by a diesel engine and synchronous generator SG. The complete dynamic model of DG requires modeling diesel engine with speed control, a SG with the system voltage control and clutch between the SG and diesel engine (Figure 5), [15-16]

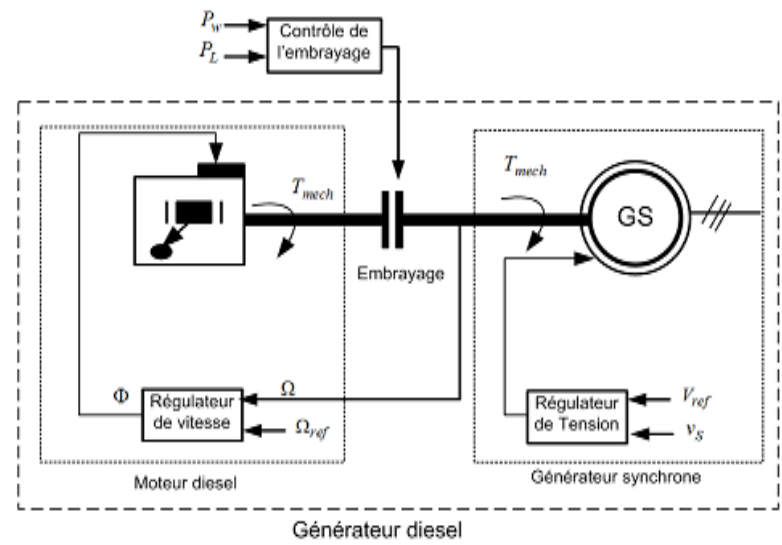

Fig 5: Model simplifies the diesel generator

\subsubsection{Diesel engine model}

The block diagram of the diesel engine is shown in Figure 6. The input signal is the speed (frequency) error and the output is the control signal of the actuator. The dynamics operation of the actuator is approximated by a transfer function with the gain $\mathrm{K}$, which adjusts the relation between the torque and the fuel consumption [17]

$$
G(s)=\frac{K .\left(1+T_{4} s\right)}{s\left(1+s T_{5}\right)\left(1+s T_{6}\right)} . I(s)
$$

Where: $\mathrm{T}_{1} \ldots . \mathrm{T}_{6}$ are the time constants.

The mechanical torque output $\mathrm{T}_{\text {mech }}$ of the diesel engine is proportional to the actual fuel flow rate $\Phi(\mathrm{s})$, but is delayed by the fuel combustion process time delay $\mathrm{T}_{\mathrm{D}}$. The mechanical torque (mechanical power) output of the diesel engine is:

$$
T_{\text {mech }}=e^{-s T_{s}} \Phi(s)
$$




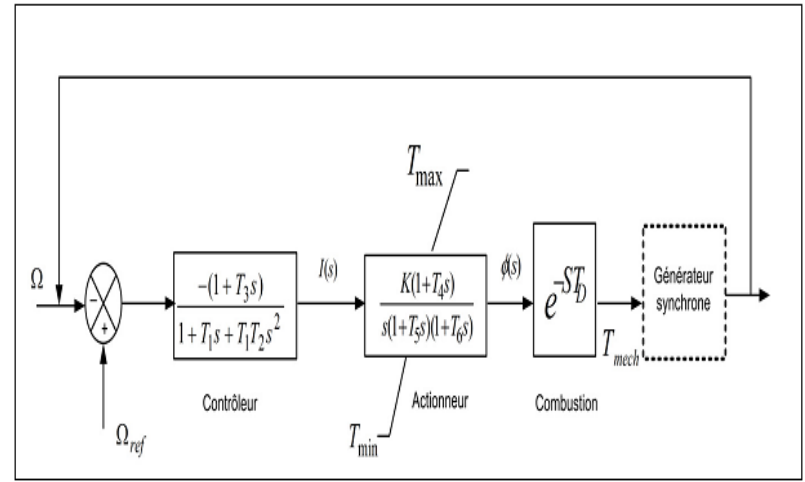

Fig 5: Simplified diesel engine block diagram

\subsubsection{Synchronous generator model}

The equivalent model of a winding of the synchronous generator is shown in Figure 6 [18]:

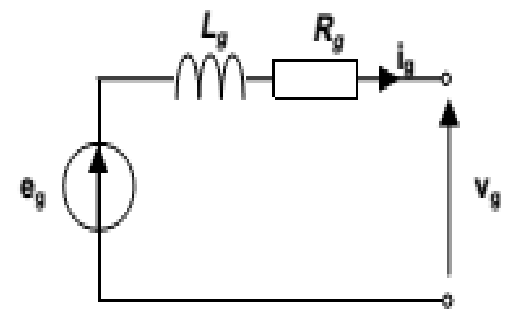

Fig 6: Equivalent model of a winding

Three phase stator has three windings and therefore three electromotive forces $\mathrm{eg}_{1}(\mathrm{t}), \mathrm{eg}_{2}(\mathrm{t})$ and $\mathrm{eg}_{3}(\mathrm{t})$ of the same root mean square (rms) value $E$ and phase shifted by $2 \pi / 3$.

The Kirchhoff's voltage law to the diagram in Figure 6 is:

$$
e_{g}=v_{g}+L_{g} \frac{d i_{g}}{d t}+R_{g} i_{g}
$$

In the simplified model of the synchronous machine, the mechanical part without friction is described by Eq. (10):

$$
J_{d s} \frac{d \Omega_{s}}{d t}=T_{d}-T_{e m}
$$

$\mathrm{J}_{\mathrm{ds}}$ : is the total inertia of the entire diesel engine synchronous generator.

$\Omega_{\mathrm{s}}$ : is the rotation speed.

$T_{d}$ : is the mechanical torque on the shaft.

$\mathrm{T}_{\mathrm{em}}$ : is the electromagnetic torque.

\subsection{Modeling of battery storage system}

In this work, it was developed a model of the $\mathrm{Ni}-\mathrm{MH}$ electrochemical battery, the equivalent circuit of the battery storage system can be represented as in Figure 7, [19]:

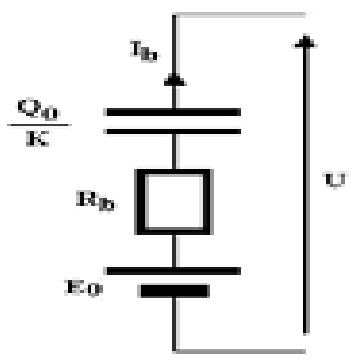

Fig 7: Electrical equivalent model of the battery

The mathematical model given by Eq. (11) that best describes the physical phenomenon of the charge and discharge is given below:

$$
U=E_{0}-K \cdot \frac{\int I_{b} \cdot d t}{Q_{0}}-R_{b} \cdot I_{b}
$$

$\mathbf{U}$ is the voltage across the battery; $\mathbf{E}_{\mathbf{0}}$ is the open circuit voltage of the charged battery, a constant $\mathbf{K}$ which depends on the battery, the internal resistance $\mathbf{R}_{\mathbf{b}}$ of the battery, the discharging current $\mathbf{I}_{\mathbf{b}}, Q_{0}$ is the ability of the battery (Ah), $\frac{\int I_{b} \cdot d t}{Q_{0}}$ shows the discharge state of the battery.

\section{RESULTS AND DISCUSSION}

The block Simulink of the isolated hybrid wind-diesel generation system with the proposed DCS is shown in Figure 8. Some of the components described before are blocks which belong to the SimPowerSystems library for MatlabSimulink.

Where: 


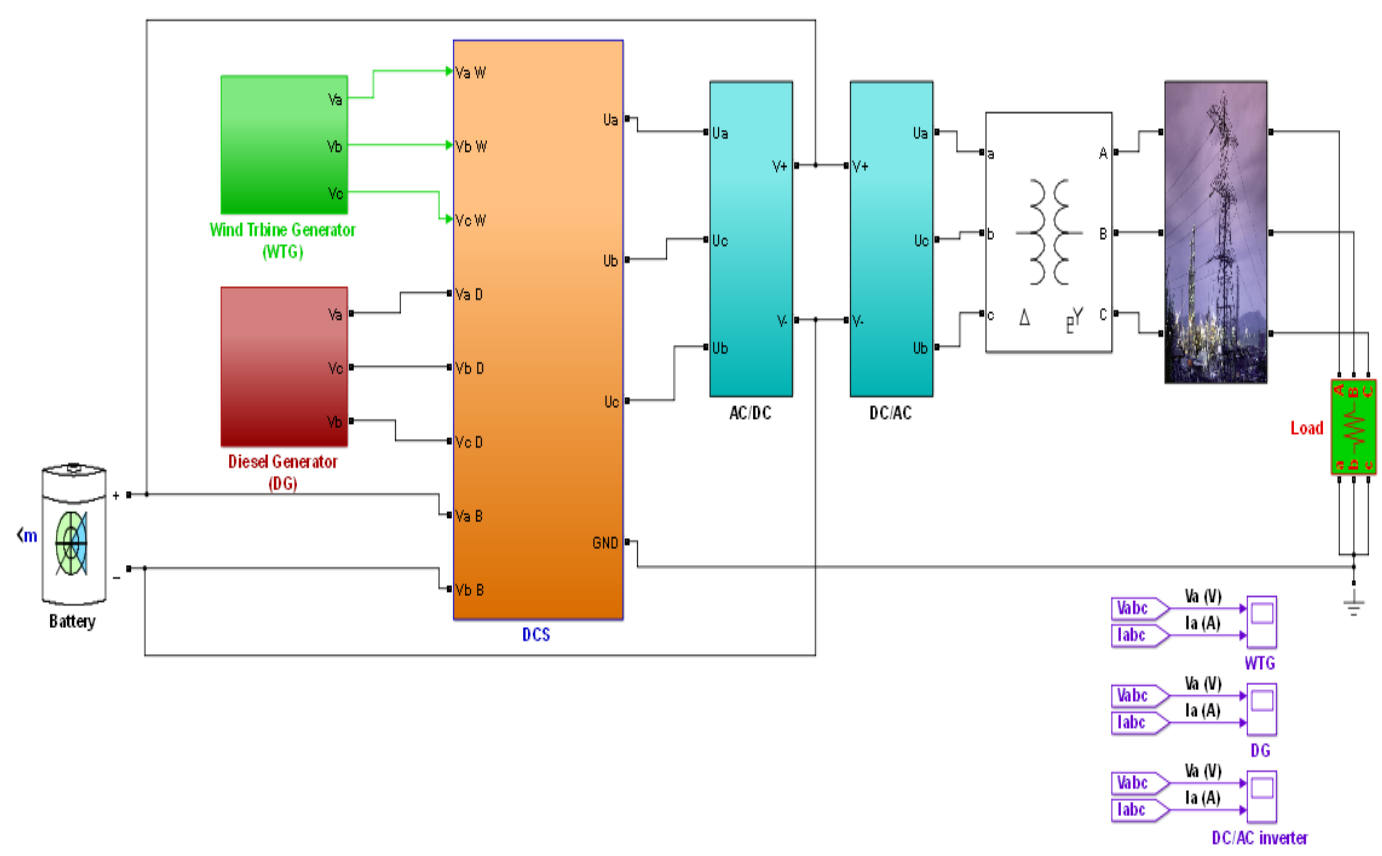

Fig 8: Global model Simulink of autonomous hybrid power system

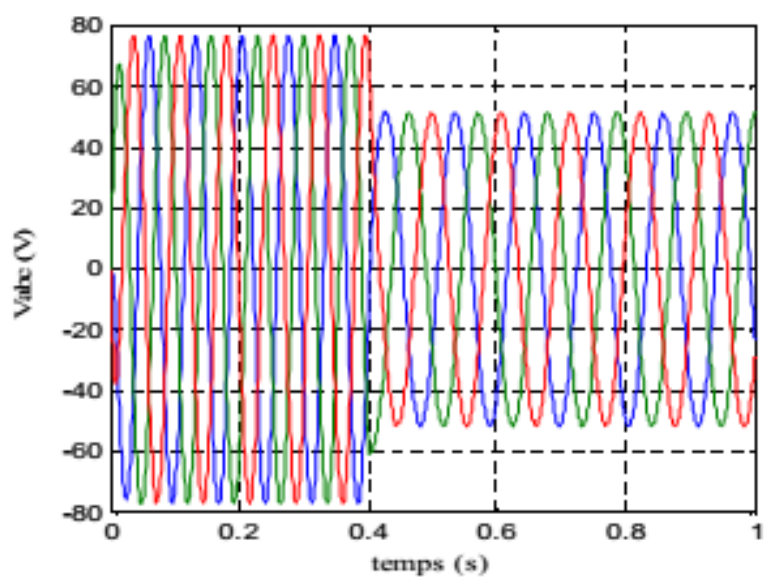

Fig 9: Three phase voltage generated by WTG

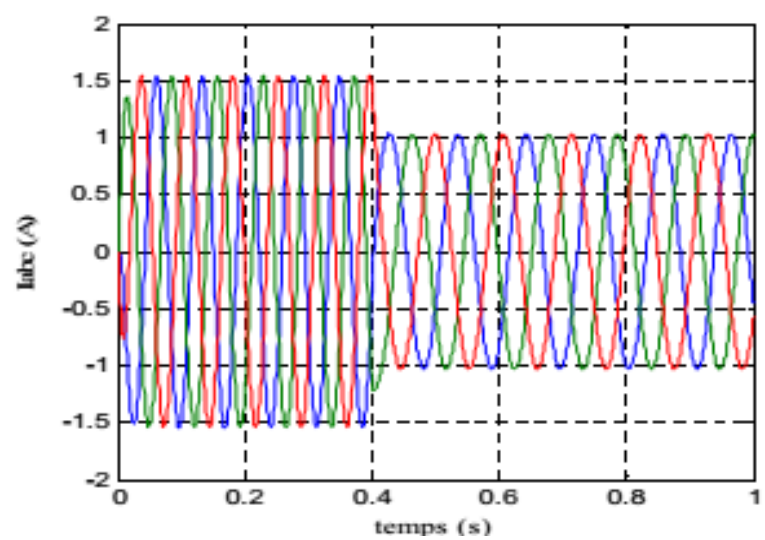

Fig 10: Three phase current generated by WTG

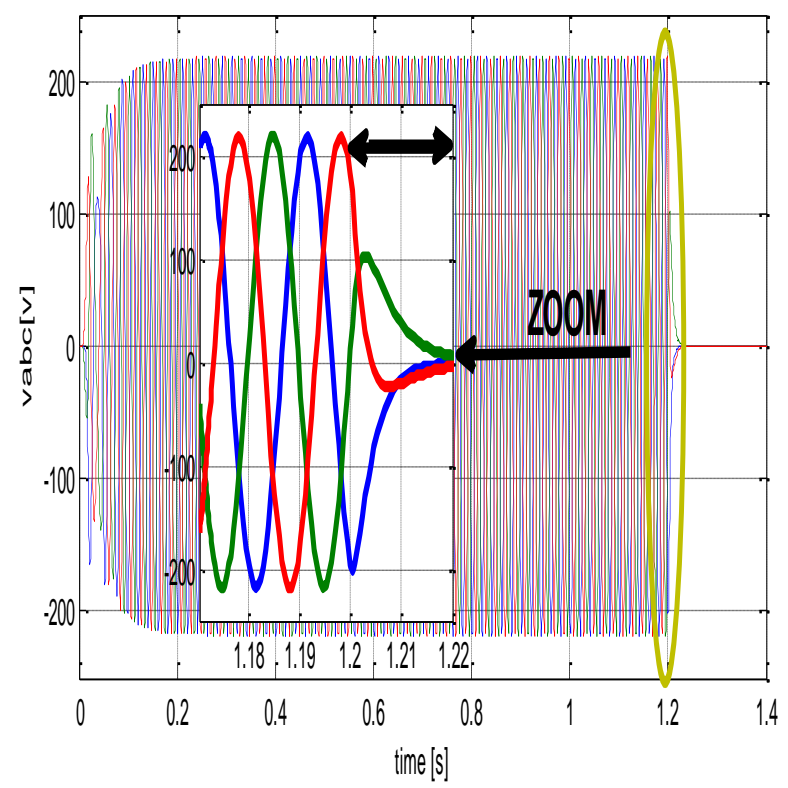

Fig 11: Three phase voltage generated by DG 


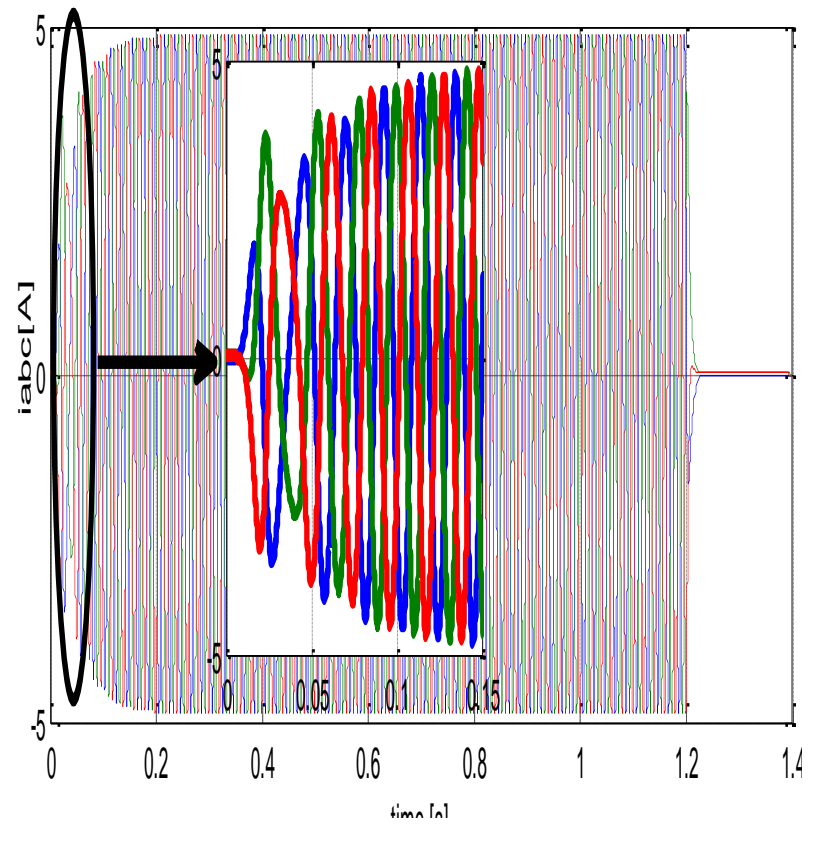

Fig 12: Three phase current generated by DG
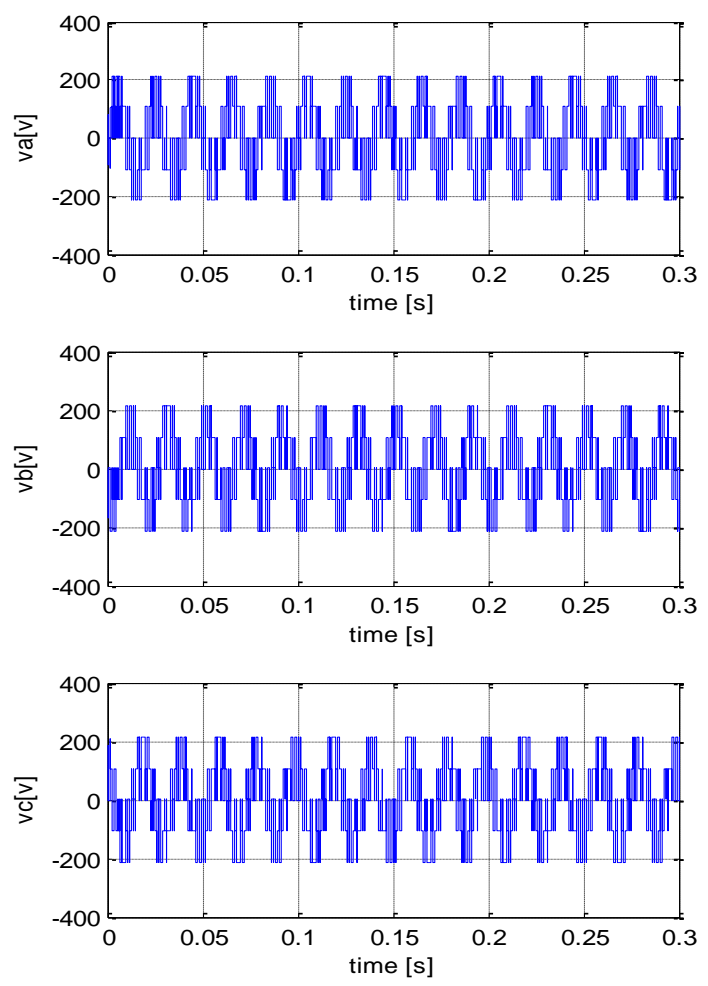

Fig 13: Output voltages of the DC/AC inverter
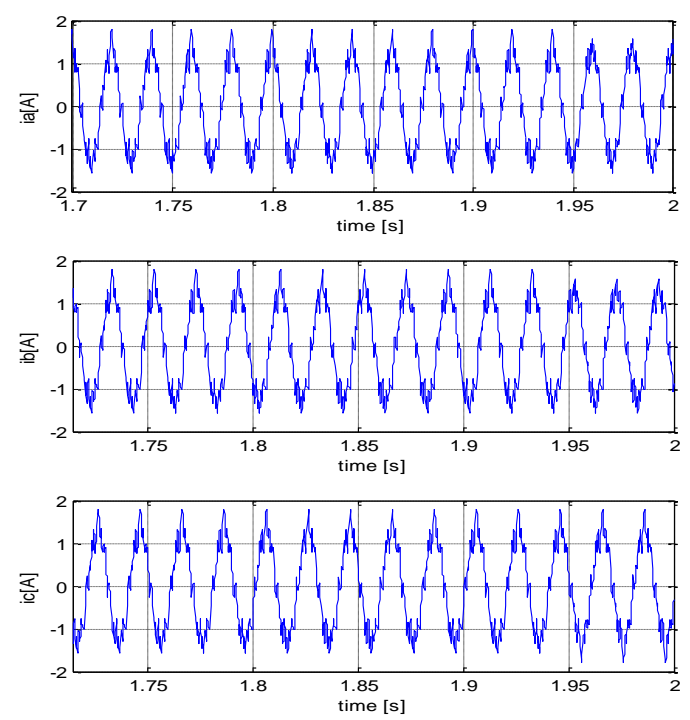

Fig 13: Output currents of the DC/AC inverter

\section{CONCLUSIONS}

This paper investigates the modeling and simulation of a wind-diesel hybrid power system for isolated areas. The simulation based on real meteorological data. The global model modeling of hybrid system is based on control strategy to optimize the power output, regulate voltage and frequency transmitted to consumers. The wind-diesel hybrid system used a high control strategy for the management of different power sources (Wind, Diesel, Battery), which ensures the openinglclosing different power switches according to meteorological conditions (wind speed). Thus the simulation models for the WDHS were developed and assembled a library of parametric models in the MATLAB/Simulink environment.

\section{REFERENCES}

[1] Luiz Antonio De Souza Ribeiro., Osvaldo Ronald Saavedra., Shigeaki Leite De Lima., José Gomes De Matos. 2011. « Isolated Micro-grids With Renewable Hybrid Generation: The Case of Lençóis Island », IEEE Transactions on Sustainable Energy Vol. 2, $\mathrm{N}^{\circ}$.1, January 2011.

[2] M.Md. Thameem Ansari., S. Velusami. 2010. « Dual mode linguistic hedge fuzzy logic controller for an isolated wind-diesel hybrid power system with superconducting magnetic energy storage unit », Energy Conversion and Management 51, 169-181.

[3] Ludovic Leclercq., Benoit Robyns., Jean-Michel Grave. 2003. « Control based on fuzzy logic of a flywheel energy storage system associated with wind and diesel generators ", Mathematics and Computers in Simulation 63, 271-280.

[4] Yu Hu., Pablo Solana. 2013. « Optimization of a hybrid diesel-wind generation plant with operational options », Renewable Energy 51, 364-372.

[5] Kasbadji Merzouk N. 2006. «Evaluation du gisement énergétique éolien contribution a la détermination du profil vertical de la vitesse du vent en Algérie ». Doctoral Thesis. Université Abou bekar Belkaid, Tlemcen-Algeria. 
[6] Weather station of the Renewable Energy Research Unit in Saharian Medium (URER-MS) Adrar, Algeria (2012). http://www.urerms.dz/.

[7] Elkhatib Kamal., Magdy Koutb., Abdul Azim Sobaih., Belal Abozalam. 2010. «An intelligent maximum power extraction algorithm for hybrid wind-diesel-storage system », Electrical Power and Energy Systems 32, 170177.

[8] H. Ibrahim., R. Younès., T. Basbous., A. Ilinca., M. Dimitrova. 2011. "Optimization of diesel engine performances for a hybrid wind-diesel system with compressed air energy storage », Energy 36, 3079-91.

[9] S. Bellarbi., N. Kasbadji merzouk., A. Malek., C. Larbes. 2013. "Modeling and simulation of wind energy chain conversion », Desalination and Water Treatment, 51:7-9, 1434-1442. Available online at: http://dx.doi.org/10.1080/19443994.2012.714452.

[10] Kassem Ahmed M., Yousef Ali M. 2011. « Robust control of an isolated hybrid wind-diesel power system using Linear Quadratic Gaussian approach », Int Electr Power Energy Syst, 33, 1092-100.

[11] Ghedmasi K., Azouzellag D. 2010. «Improvement of performances for wind energy conversions systems », Int Electr Power Energy Syst 32, 936-45.

[12] B. Sedaghat., A. Jalilvand., R. Noroozian. 2012. « Design of a multilevel control strategy for integration of stand-alone wind/diesel system », Electrical Power and Energy Systems 35, 123-137.
[13] Elkhatib Kamal., Magdy Koutb., Abdul Azim Sobaih., Belal Abozalam. 2010. «An intelligent maximum power extraction algorithm for hybrid wind-diesel-storage system », Electrical Power and Energy Systems 32, 170 177

[14] Khaireddine Allali., El Bahi Azzag. 2015. « Study of wind-diesel hybrid power system integration in the South Algerian », Journal of Frontiers in Energy, in press.

[15] Miloud Rezkallah. 2010. « Amélioration de la qualité d'énergie fournie au réseau autonome hybride éoliendiesel », M.ing, université du Québec.

[16] Khaireddine Allali., El Bahi Azzag. 2013. « Study of Wind-Diesel Hybrid System for Electrification of Isolated Sites »,World Academy of Science, Engineering and Technology 78, 984-988.

[17] Yeager, K. E., J. R. Willis. 1993. « Modeling of emergency diesel generators in an 800 megawatt nuclear power plant », IEEE Transactions on Energy Conversion, Vol. 8, $\mathrm{N}^{\circ} .3$, p. 433-41.

[18] MATLAB/Simulink.www.mathworks.com/access/helpde sk/help/toolbox/physmod/powersys/simplifiedsynchrono usmachine.html, 2005.

[19] D. Rekioua., Z. Roumila., T. Rekioua.2008. « Study of a hybrid solar power station - wind - diesel », Journal of Renewable Energy Vol. $11 \mathrm{~N}^{\mathrm{o}}$. 4, 623-633. 